\title{
Impact of Ketamine on Opioid Use and Persistent Pain After Cytoreductive Surgery with Hyperthermic Chemotherapy
}

Juan P Cata (D) ${ }^{1,2}$

Pascal Owusu-Agyemang 1,2

Dhanalakshmi Koyyalagunta $^{3}$

German Corrales ${ }^{1,2}$

Lei Feng ${ }^{4}$

Keith Fournier ${ }^{2,3}$

'Department of Anesthesiology and Perioperative Medicine, The University of Texas MD Anderson Cancer Center, Houston, TX, USA; ${ }^{2}$ Anesthesiology and Surgical Oncology Research Group, Houston, TX, USA; ${ }^{3}$ Department of Surgical Oncology, The University of Texas MD Anderson Cancer Center, Houston, TX, USA; ${ }^{4}$ Department of Biostatistics, The University of Texas MD Anderson Cancer Center, Houston, TX, USA
Correspondence: Juan P Cata

Department of Anesthesiology and Perioperative Medicine, The University of Texas MD Anderson Cancer Centre, Houston, TX, USA

Tel +l 7/3-792-4582

$\mathrm{Fax}+|7| 3-792-4582$

Email JCata@mdanderson.org
Background: Persistent pain and opioid use can be devastating after cytoreductive surgery (CRS) and hyperthermic intraoperative chemotherapy (HIPEC).

Methods: We conducted a retrospective study to investigate the impact of ketamine use on postoperative complications and persistent and chronic pain after CRS-HIPEC.

Results: Ketamine reduced perioperative opioid use before and after implementation of recovery after surgery programs. Ketamine did not impact the formation of persistent and chronic pain formation and long-term opioid use. Postoperative complications and postoperative reoperations were independent predictors of persistent pain. Interestingly, the risk of having a complication was increased by $1 \%$ for every doubling in opioids used intraoperatively.

Conclusion: Ketamine use reduces perioperative opioid consumption in patients undergoing CRS-HIPEC, but it is not associated with improvements in long-term opioid use and chronic pain.

Keywords: chronic pain, cancer, neoplasm, opioids, ketamine, surgery, cytoreductive surgery

\section{Introduction}

Cytoreductive surgery (CRS) with hyperthermic intraperitoneal chemotherapy (HIPEC) is increasingly offered as a treatment option for patients with peritoneal spread of appendiceal, colorectal, peritoneal mesothelioma, gastric carcinoma, and more recently to gynecological malignancies. ${ }^{1-3}$ CRS-HIPEC involves extensive peritoneal stripping, multi-organ resections, and the intraperitoneal administration of heated (up to $42^{\circ} \mathrm{C}$ ) chemotherapy agents (eg, mitomycin $\mathrm{C}$, cisplatin or oxaliplatin). ${ }^{4}$

After CRS-HIPEC, acute pain can be severe and, in many patients, difficult to treat. $^{5}$ The current perioperative management of CRS-HIPEC related pain relies on multimodal analgesia strategies using regional anesthesia and systemic analgesics, including opioids. ${ }^{6,7}$ Unfortunately, abdominal pain may remain undertreated for some patients, and can lead to the consumption of large amounts of opioids that can be as high $1000 \mathrm{mg}$ of morphine equivalent daily. ${ }^{7,8}$ In those patients, high opioid consumption is an independent risk factor for postoperative adverse outcomes, delayed recovery and persistent postoperative opioid use. ${ }^{9}$

Ketamine is a N-methyl-D- aspartate receptor antagonist that at high doses has anesthetic effects but at low doses is a potent analgesic. ${ }^{10}$ Ketamine has opioidsparing effects and delays the time of first-time opioid dose after major surgery. ${ }^{11,12}$ 
Clinical studies demonstrate that ketamine does not show significant clinical effects on the reduction of persistent postsurgical pain. ${ }^{13,14}$ However, a randomized controlled trial by De Kock et al demonstrated that intravenous ketamine $(0.5 \mathrm{mg} / \mathrm{kg}$ bolus followed by an infusion of $0.25 \mathrm{mg} / \mathrm{kg}$ per $\mathrm{h}$ ) reduced analgesic use one, six and 12 months after open laparotomy. ${ }^{15}$

We consider important to find strategies to effectively treat pain and reduce acute and long-term exposure to opioids after CRS-HIPEC. The impact of low intraoperative doses of ketamine on acute, persistent, and chronic pain and opioid use after CRS-HIPEC is unknown. Here, we tested the hypothesis that a low dose of intravenous ketamine intraoperatively is associated with a significant reduction in opioid use perioperatively and long term after CRS-HIPEC.

\section{Materials and Methods}

This was a retrospective study approved by the Institutional Review Board (IRB) of the University of Texas MD Anderson Cancer Center (PA 14-0160). After obtaining waiver of informed consent and according to data confidentiality and compliance with the Declaration of Helsinki, we collected demographic, disease status, and perioperative data of patients 18 years of age or older who were treated with CRS-HIPEC for appendiceal malignancy between January 2006 and August 2018. We excluded patients who had CRS-HIPEC surgery for recurrent disease and those with missing data on the primary and secondary endpoints.

Our treatment variable was the use of ketamine $\mathrm{HCl}$ (Ketalar, Hospira Inc, Illinois, USA) intraoperatively. In our institution, ketamine entered routinely as part of the analgesic armamentarium for CRS-HIPEC in 2012 during the implementation of enhanced recovery after surgery (ERAS). Ketamine was administered intraoperatively according to the attending anaesthesiologist clinical judgment. Typically, ketamine was given as an intravenous bolus of $0.5-1 \mathrm{mg} / \mathrm{kg}$ followed by a continuous infusion of $1-5 \mathrm{mcg} / \mathrm{kg} / \mathrm{min}$. The primary outcome of the study was persistent pain after CRS-HIPEC. Persistent pain was defined as any abdominal pain six months after surgery. Secondary outcomes included intraoperative, inpatient postoperative opioid use, chronic pain (one year after surgery), length of stay and postoperative complications using Clavien-Dindo scale. We used morphine equivalent daily dose (MEDD) to quantify opioid consumption.

\section{Statistical Analysis}

Patients' demographics, disease status, and outcomes were summarized through descriptive statistics. Logarithmic transformation to base 2 was performed to the variables, which were not normally distributed in the original scale. Wilcoxon rank-sum tests were used to compare location parameters of continuous distributions between patient groups. Fisher's exact or Chi-square test was used to evaluate the association between two categorical variables. The multivariate logistic regression model was used to evaluate the effect of important covariates on the status of postoperative complication. All clinical important covariates were included in the full model for model selection. A backward model selection method was used and included covariates with a $p$-value less than 0.20 . A $p<$ 0.05 was considered statistically significant. We did not perform a sample size analysis because the effect size of the ketamine in this patient population is unknown. Statistical software SAS 9.4 (SAS, Cary, NC) was used for all the analyses.

\section{Results}

\section{Overall Cohort of Patients}

A total of 329 patients were included in the study. Overall, the median (range) age of the patient population was 53.8 (18-75) years old. There were more women $(n=206$, $62.6 \%)$ than men $(n=123,37.4 \%)$ patients, and the most common ASA physical status was $3(85.4 \%)$. The most common tumour grade was low $(n=220,66.9 \%)$ and $94.2 \% \quad(n=310) \quad$ were treated with mitomycin $\mathrm{C}$ intraoperatively. Despite fifty-three patients not having a cytoreductive score, the most common score was 1 (67.57\%). The median (range) MEDD received intraoperatively and postoperatively was $58(0-9185)$ and $907.7(0-$ $28,307.6)$. Sixty-eight percent $(\mathrm{n}=223)$ of the patients had a complication postoperatively, and in 52 of them (15.8\%) the severity was 3 or higher on the Clavien-Dindo scale.

In terms of postoperative pain, $31.1 \%(\mathrm{n}=87), 12.3 \%$ $(n=22)$ and $9.6 \%(n=16)$ of the patients were reporting pain one, six (persistent) and 12 (chronic) months after surgery. Overall, pain was mild since the median pain scores one, six and 12 months after surgery were 3, 3, and 3.5 on the verbal numerical rating scale for the patients with pain. Remarkably, $79.9 \%(n=231)$ of the patients were taking opioid one month postoperatively. The rate of opioid use diminished six $(21.0 \%, \mathrm{n}=53)$ and twelve $(12.9 \%, \mathrm{n}=30)$ months after surgery. 
In 2012, we started our ERAS in CRS-HIPEC patients. One of the goals of ERAS programs is to reduce opioids perioperatively; therefore, we conducted a subanalysis in patients who received (or not) ketamine after 2012. The subanalysis included 224 patients, of whom 99 subjects received ketamine, and 125 did not receive (Table 1). Those in the ketamine group were slightly younger and more likely to have an ASA 1-2. Other demographic and tumour-related variables were not statistically significant.

One month after surgery, $79 \%(\mathrm{n}=253)$ of the patients were taking opioids ( $\mathrm{n}=40$ missing data). Among the 253 patients with information (76 with missing data) on opioid use six months postoperatively, 53 of them were taking opioids (20.95\%). Lastly, one year after surgery, 12.93\% $(n=30$ out of 202) of the patients were taking opioids one year after surgery.

\section{Association Between Ketamine and Opioid Consumption}

About a third of the patients $(\mathrm{n}=99,30.1 \%)$ received ketamine intraoperatively. As shown in Table 1, patients who received ketamine had significantly lower low tumour grades, had a higher rate of neoadjuvant therapy administration and underwent long surgical procedures. The analysis demonstrated that opioid consumption intraoperatively and during admission to the nursing ward was significantly lower in patients who received ketamine (Table 2). Briefly, patients treated with ketamine had a nearly 7-fold decrease in the median use of opioids intraoperatively and received more than 200 MEDD less than those who did not receive ketamine.

After ERAS, the analysis showed that ketamine-treated subjects had a statistically significant lower consumption of intravenous opioids in morphine equivalents (median [range]: 15 [0-111] mg than those not receiving the analgesic (44, [0260], Table 2). While the postoperative opioid consumption was also lower in the ketamine group (751.2, [9.3-5928]) than in the no ketamine group (813.1, [0-8,727.4]), and the difference was not statistically significant $(\mathrm{p}=0.085)$. The rate of opioid use one, six, and twelve months after surgery were not significantly different between the groups (Table 3).

\section{Association Between Ketamine, Persistent and Chronic Pain}

Overall, ketamine was not significantly associated with lower pain scores one, six, and twelve months after surgery.

Table I Demographic Characteristics

\begin{tabular}{|c|c|c|c|c|c|c|c|}
\hline \multirow[t]{2}{*}{ Variable } & & \multicolumn{3}{|c|}{ All Patients $(n=329)$} & \multicolumn{3}{|c|}{ Post-ERAS (n=224) } \\
\hline & & Ketamine No & Ketamine Yes & p- value & Ketamine No & Ketamine Yes & p-value \\
\hline Age, years & Median (Range) & $53.93(23.2-74.2)$ & $53.69(17.7-75.0)$ & 0.430 & $58.18(23.2-74.2)$ & $53.69(17.7-75.0)$ & 0.008 \\
\hline BMI & Median (Range) & $27.25(16.2-48.9)$ & $27.05(|7.6-5| .5)$ & 0.842 & $27.13(16.2-48.4)$ & $27.05(|7.6-5| .5)$ & 0.770 \\
\hline Gender & $\begin{array}{l}\text { Female } \\
\text { Male }\end{array}$ & $\begin{array}{l}|4|(6 \mid .3 \%) \\
89(38.7 \%)\end{array}$ & $\begin{array}{l}65 \text { (65.7\%) } \\
34(34.3 \%)\end{array}$ & 0.454 & $\begin{array}{l}74(59.2 \%) \\
51 \text { (40.8\%) }\end{array}$ & $\begin{array}{l}65 \text { (65.7\%) } \\
34(34.3 \%)\end{array}$ & 0.323 \\
\hline $\begin{array}{l}\text { ASA physical } \\
\text { Status }\end{array}$ & $\begin{array}{l}1 / 2 \\
3 / 4\end{array}$ & $\begin{array}{c}35(15.2 \%) \\
195(84.8 \%)\end{array}$ & $\begin{array}{l}10(10.1 \%) \\
89(89.9 \%)\end{array}$ & 0.215 & $\begin{array}{c}4(3.2 \%) \\
12 \mid(96.8 \%)\end{array}$ & $\begin{array}{l}10(10.1 \%) \\
89(89.9 \%)\end{array}$ & 0.050 \\
\hline $\begin{array}{l}\text { Neoadjuvant } \\
\text { Chemotherapy }\end{array}$ & $\begin{array}{l}0 \\
1\end{array}$ & $\begin{array}{l}168(73 \%) \\
62(27 \%)\end{array}$ & $\begin{array}{l}62(62.6 \%) \\
37(37.4 \%)\end{array}$ & 0.059 & $\begin{array}{l}80(64 \%) \\
45(36 \%)\end{array}$ & $\begin{array}{l}62(62.6 \%) \\
37(37.4 \%)\end{array}$ & 0.832 \\
\hline $\begin{array}{l}\text { Cigarette } \\
\text { Smoking }\end{array}$ & $\begin{array}{l}\text { No } \\
\text { Yes }\end{array}$ & $\begin{array}{c}226(98.3 \%) \\
4(1.7 \%)\end{array}$ & $\begin{array}{c}96(97 \%) \\
3(3 \%)\end{array}$ & 0.434 & $\begin{array}{c}123(98.4 \%) \\
2(1.6 \%)\end{array}$ & $\begin{array}{c}96(97 \%) \\
3(3 \%)\end{array}$ & 0.657 \\
\hline $\begin{array}{l}\text { Tumor } \\
\text { Grade }\end{array}$ & $\begin{array}{l}\text { High } \\
\text { Intermediate } \\
\text { Low }\end{array}$ & $\begin{array}{l}29(12.6 \%) \\
38(16.5 \%) \\
163(70.9 \%)\end{array}$ & $\begin{array}{l}14(14.1 \%) \\
28(28.3 \%) \\
57(57.6 \%)\end{array}$ & 0.035 & $\begin{array}{c}24(19.2 \%) \\
31(24.8 \%) \\
70(56 \%)\end{array}$ & $\begin{array}{l}14(14.1 \%) \\
28(28.3 \%) \\
57(57.6 \%)\end{array}$ & 0.574 \\
\hline $\begin{array}{l}\text { Chemotherapy } \\
\text { Perfusion type }\end{array}$ & $\begin{array}{l}\text { Cis/Oxaliplatin } \\
\text { Mitomycin }\end{array}$ & $\begin{array}{c}11(4.8 \%) \\
219(95.2 \%)\end{array}$ & $\begin{array}{c}8(8.1 \%) \\
91 \text { (91.9\%) }\end{array}$ & 0.240 & $\begin{array}{c}9(7.2 \%) \\
116(92.8 \%)\end{array}$ & $\begin{array}{c}8(8.1 \%) \\
91(91.9 \%)\end{array}$ & 0.805 \\
\hline Peritoneal carcinomatosis index & Median (Range) & $17(2-39)$ & $15(2-39)$ & 0.177 & $18(2-39)$ & $15(2-39)$ & 0.188 \\
\hline Anest duration (min) & Median (Range) & $622(331-1101)$ & $555(379-1019$ & 0.007 & $628.14(148.82)$ & $599.59(144.15)$ & 0.080 \\
\hline
\end{tabular}

Abbreviations: BMI, body mass index; ASA, American society of Anesthesiologists; Cis, cisplatin; Anest, anesthesia; Min, minutes. 
Table 2 Effect of Perioperative Opioid Use, Length of Stay and Complications

\begin{tabular}{|c|c|c|c|c|c|c|c|}
\hline & & \multicolumn{3}{|c|}{ All Patients $(n=329)$} & \multicolumn{3}{|c|}{ Post-ERAS $(n=224)$} \\
\hline & & Ketamine No & $\begin{array}{l}\text { Ketamine } \\
\text { Yes }\end{array}$ & $\mathbf{P}$ value & $\begin{array}{l}\text { Ketamine } \\
\text { No }\end{array}$ & Ketamine Yes & P value \\
\hline $\begin{array}{l}\text { Intraoperative opioid use, } \mathrm{mg} \text { (morphine } \\
\text { equivalents) }\end{array}$ & & $\begin{array}{l}101.25(0- \\
9185)\end{array}$ & $15(0-111)$ & $<0.001$ & $44(0-260)$ & $15(0-111)$ & $<0.0001$ \\
\hline $\begin{array}{l}\text { Postoperative opioid use, mg (morphine } \\
\text { equivalents) }\end{array}$ & & $\begin{array}{l}977.7(40- \\
28,307.6)\end{array}$ & $\begin{array}{c}751.2(9.3- \\
5928)\end{array}$ & 0.004 & $\begin{array}{l}813.1(0- \\
8.727 .4)\end{array}$ & $\begin{array}{c}751.2(9.3- \\
5.928 .0)\end{array}$ & 0.085 \\
\hline Length of stay (days) & & $15.5(5-113)$ & $10(6-68)$ & $<0.0001$ & $12(5 \sim 72)$ & $10(6 \sim 68)$ & 0.009 \\
\hline \multirow[t]{2}{*}{ Postoperative complications } & No & $63(27.4 \%)$ & 43 (43.4\%) & 0.0043 & $43(34.4 \%)$ & 43 (43.4\%) & 0.167 \\
\hline & Yes & $167(72.6 \%)$ & $56(56.6 \%)$ & & $82(65.6 \%)$ & $56(56.6 \%)$ & \\
\hline
\end{tabular}

Table 3 Effect of Ketamine on Persistent and Chronic Pain and Opioid Use

\begin{tabular}{|c|c|c|c|c|c|c|c|}
\hline & & \multicolumn{3}{|c|}{ All Patients $(n=329)$} & \multicolumn{3}{|c|}{ Post-ERAS $(n=224)$} \\
\hline & & \multicolumn{6}{|c|}{ One Month Postoperatively } \\
\hline & & Ketamine No & Ketamine Yes & $P$ value & Ketamine No & Ketamine Yes & $P$ value \\
\hline Any opioid & No & 38 (19\%) & $20(22.5 \%)$ & 0.496 & 23 (19.7\%) & 20 (22.5\%) & 0.623 \\
\hline Use & Yes & $162(81 \%)$ & 69 (77.5\%) & & 94 (80.3\%) & 69 (77.5\%) & \\
\hline Any pain & No & $136(69.4 \%)$ & 57 (67.9\%) & 0.800 & 75 (65.8\%) & 57 (67.9\%) & 0.760 \\
\hline & Yes & $60(30.6 \%)$ & 27 (32.1\%) & & 39 (34.2\%) & 27 (32.1\%) & \\
\hline Pain $(0-10)$ & & $0(0-9)$ & $0(0-8)$ & 0.795 & $0(0-9)$ & $0(0-8)$ & 0.358 \\
\hline \multicolumn{8}{|c|}{ Six Months Postoperatively } \\
\hline Any opioid & No & I 43 (79.9\%) & 57 (77\%) & 0.611 & 75 (77.3\%) & 57 (77\%) & 0.964 \\
\hline Use & Yes & $36(20.1 \%)$ & $17(23 \%)$ & & $22(22.7 \%)$ & $17(23 \%)$ & \\
\hline Any pain & No & $106(89.1 \%)$ & 51 (85\%) & 0.433 & $68(88.3 \%)$ & $51(85 \%)$ & 0.569 \\
\hline & Yes & $13(10.9 \%)$ & $9(15 \%)$ & & $9(11.7 \%)$ & $9(15 \%)$ & \\
\hline Pain $(0-10)$ & & $0(0-7)$ & $0(0-5)$ & 0.442 & $0(0-7)$ & $0(0-5)$ & 0.584 \\
\hline \multicolumn{8}{|c|}{ Twelve Months Postoperatively } \\
\hline Opioid & No & I47 (88\%) & 55 (84.6\%) & $0.487 I$ & 78 (85.7\%) & 55 (84.6\%) & 0.849 \\
\hline & Yes & $20(12 \%)$ & $10(15.4 \%)$ & & $13(14.3 \%)$ & $10(15.4 \%)$ & \\
\hline Any pain & No & $102(87.9 \%)$ & $48(96 \%)$ & 0.152 & $53(84.1 \%)$ & $48(96 \%)$ & 0.063 \\
\hline Use & Yes & 14 (12.1\%) & $2(4 \%)$ & & $10(15.9 \%)$ & $2(4 \%)$ & \\
\hline Pain $(0-10)$ & & $0(0-10)$ & $0(0-4)$ & 0.113 & $0(0-10)$ & $0(0-4)$ & 0.045 \\
\hline
\end{tabular}

Also, we investigated the impact of ketamine on persistent and chronic pain in patients who were part of our ERAS program. The proportion of patients complaining of pain and the pain severity one and six months after surgery was similar between patients treated with and without ketamine. Notably, the median [range] severity of pain 12 months after surgery was lower in those treated with ketamine (0: [0-4]) than in patients who did not receive the drug $(0[0-10])$, $\mathrm{p}=0.045$ ). Since new surgeries occurring within the year of the CRS-HIPEC procedure could influence opioid intake and the presence of chronic, we investigated the rate of reoperations in both groups of patients. The data indicate that there were no significant differences in the rates of reoperations six and 12 months after the CRS-HIPEC surgery 
for both groups of patients (Table 3). We used a multivariate logistic regression model to evaluate the effect of covariates on pain at six months. We observed that the presence of any postoperative complications (odds ratio, OR; 95\% confidence interval, CI: 5.4, 1.53-18.99, $\mathrm{p}=0.008)$ and postoperative re-operations (OR, 95\% CI: 19.45, 1.63-232.16, $\mathrm{p}=0.01$ ) were independent predictors of persistent pain.

\section{Association Between Ketamine, Length of Stay and Postoperative Complications}

Opioids are associated with postoperative complications and increased length of stay. Our data indicate that ketamine has opioid-sparing effects. Therefore, we investigated whether ketamine was associated with a reduction in postoperative complications and shorter length of stay in our cohort of patients. The statistical analysis demonstrated that patients treated with ketamine (10 [6-68] days) stayed 5 days less in the hospital than those who did not receive this drug (15.5 [5-113] days), $\mathrm{p}<0.001$, Table 2). Remarkably, patients in the ketamine group had also fewer postoperative complications $(n=56,56.6 \%)$ than those in the non-ketamine group $(\mathrm{n}=167,72.6 \%, \mathrm{p}=0.004)$. However, this observation was not statistically significant in the ERAS cohort of patients (Table 2).

The multivariate logistic regression model used to evaluate the effect of covariates on postoperative complications after implementation of ERAS demonstrated that the duration of anaesthesia (OR, 95\% CI: 1.004, 1.002$1.006, \mathrm{p}<0.001)$ and mitomycin use (OR, 95\% CI: 3.29, $1.86-0.96, p=0.035)$ were independent risk factors. While ketamine was not an independent risk factor associated with a reduction in postoperative complications, the odds of having a postoperative complication were increased by $1 \%$ for every doubling in MEDD used intraoperatively (OR, 95\% CI: 1.1, 1.03-1.17, $\mathrm{p}=0.004)$.

\section{Discussion}

This retrospective study suggests that intravenous ketamine can significantly reduce opioids perioperatively when given during CRS-HIPEC surgery but does not decrease the formation of persistent and chronic pain. In support of this finding, different studies indicate that ketamine has opioidsparing effects when it is administered during major surgery. ${ }^{16,17}$ For instance, intravenous ketamine was associated with a reduction of approximately $50 \mathrm{mg}$ of morphine equivalents during cardiac surgery, which is similar to the decrease of $47 \mathrm{mg}$ found in our study. ${ }^{16}$ Our work also shows that patients treated with ketamine required less opioids postoperatively. While the reduction in the median opioid use (226.5 mg morphine equivalents) was statistically significant when we included patients before ERAS, the observed difference in ERAS patients did not reach statistical significance. The current evidence indicates that ketamine has opioid-sparing effects in the postoperative period. For instance, a recent meta-analysis that included 8431 patients from 130 studies demonstrated intravenous ketamine was associated with a 24- and 48-hours reduction in opioids of $8 \mathrm{mg}$ and $13 \mathrm{mg}$, respectively. ${ }^{18}$ Therefore, we consider that a median reduction of $62 \mathrm{mg}$ of morphine equivalents is clinically relevant.

High dosages of opioids can slow the postoperative recovery of patients since they are associated with postoperative complications. ${ }^{19}$ Ketamine has well-documented postoperative opioid-sparing effects. ${ }^{20,21}$ Here, we demonstrate that ketamine was associated with a statistically significant reduction in postoperative complications when we included patients outside ERAS pathways (before 2012). However, the effect on complications was not observed when the analysis was restricted to patients who had surgery after the year 2012, suggesting that the substantial reduction in opioid use associated with ketamine is more impactful in patients outside ERAS pathways. However, it is worth considering that our analysis could have been underpowered to demonstrate a significant effect in patients post ERAS implementation, since we observed a $9 \%$ reduction in complications between patients who were treated and not treated with ketamine.

Persistent and chronic postsurgical pain is a debilitating complication of major abdominal surgery. ${ }^{22}$ Here, we report that $12.3 \%$ and $9.6 \%$ of the patients reported pain at six and 12 months after surgery. These incidences are similar to those reported in two different studies that included a mixed surgical population of patients. ${ }^{23,24}$ In our cohort of patients, reoperations and postoperative complications were associated with persistent postoperative pain. It has been theorized that ketamine could reduce the incidence of postsurgical persistent and chronic pain. ${ }^{25}$ Chaparro et al recently demonstrated in a systematic review that intravenous ketamine in comparison to placebo significantly reduced by $50 \%$ the risk of persistent pain six months postoperatively. ${ }^{26}$ However, most recent evidence contradicts Chaparro's findings. ${ }^{27}$ Here, we could not demonstrate a significant difference in chronic pain after CRS-HIPEC surgery between those treated with and without ketamine. However, our analysis showed that $15.9 \%$ of the patients not receiving ketamine complained of chronic pain (at 12 months) in comparison to $4 \%$ in the 
ketamine group, suggesting a possible protective effect. The lack of strong association between the use of ketamine and postoperative persistent and chronic pain in our patient population can be explained by the fact that new surgical trauma due to postoperative complications is an independent risk factor for chronic pain and those patients with re-operations might not have received ketamine during their redosurgeries.

We also investigated whether ketamine was associated with a reduction in long-term opioid use since patients with chronic pain might receive these analgesics as part of their analgesic treatment. Our study demonstrated that ketamine was not associated with a decrease in the incidence of persistent and chronic opioid use. Our findings agree with previous studies. ${ }^{28-30}$ For instance, in a study by Nielsen et al ketamine did not reduce persistent opioid (six months) use after spine surgery. $^{28}$ Similarly, a randomized controlled trial conducted by Chumbley et al showed that ketamine did not cause a reduction in opioid use six and 12 months after thoracic surgery. ${ }^{29}$

Our study has significant limitations. First, this was a retrospective study. Unknown factors can influence (confounding) the findings of our analysis (ie, preoperative exposure to opioids). The long duration of observation, over which multiple factors were likely to be changing can further confound our results. We tried to adjust for such changes in practice by dividing the period of observation in those before and after ERAS implementation. Second, the duration of the infusion of ketamine was limited to the intraoperative period. Extending the duration of the administration of ketamine might have been associated with a reduction in the transition from acute to persistent to chronic pain. Third, the presence of persistent and chronic pain and its intensity were retrospectively collected from electronic medical records; thus, the rates presented here might have been underestimated. Last, we could not quantify opioid consumption sixth and 12 months of surgery. Therefore, our study did not address any potential longterm opioid-sparing effect of ketamine. This is a retrospective study of a single centre; therefore, the generalizability of the results is limited to the population of patients included in this work, and our findings should be considered carefully.

In conclusion, the infusion of ketamine intravenously during CRS-HIPEC is associated with short-term opioidsparing effects but does not have significant effects on postoperative persistent and chronic opioid use and pain.
The results of the present study need to be validated in a randomized controlled trial.

\section{Author Contributions}

All authors made a significant contribution to the work reported, in the conception, study design, execution, acquisition of data, analysis and interpretation and gave final approval of the version to be published. All authors have agreed on the journal to which the article has been submitted and agree to be accountable for all aspects of the work.

\section{Disclosure}

The authors report no conflicts of interest in this work.

\section{References}

1. van Driel WJ, Koole SN, Sikorska K, et al. Hyperthermic intraperitoneal chemotherapy in ovarian cancer. $N$ Engl J Med. 2018;378 (3):230-240. doi:10.1056/NEJMoa1708618

2. Desiderio J, Chao J, Melstrom L, et al. The 30-year experience-A meta-analysis of randomised and high-quality non-randomised studies of hyperthermic intraperitoneal chemotherapy in the treatment of gastric cancer. Eur $J$ Cancer. 2017;79:1-14. doi:10.1016/j. ejca.2017.03.030

3. Levinsky NC, Morris MC, Wima K, et al. Should we be doing cytoreductive surgery with HIPEC for signet ring cell appendiceal adenocarcinoma? A study from the US HIPEC collaborative. J Gastrointest Surg. 2019;24(1):155-164.

4. Begossi G, Gonzalez-Moreno S, Ortega-Perez G, Fon LJ, Sugarbaker PH. Cytoreduction and intraperitoneal chemotherapy for the management of peritoneal carcinomatosis, sarcomatosis and mesothelioma. Eur J Surg Oncol. 2002;28(1):80-87. doi:10.1053/ ejso.2001.1152

5. Wang X, Li T. Postoperative pain pathophysiology and treatment strategies after CRS + HIPEC for peritoneal cancer. World $J$ Surg Oncol. 2020;18(1):1-8. doi:10.1186/s12957-020-01842-7

6. Owusu-Agyemang P, Soliz J, Hayes-Jordan A, Harun N, Gottumukkala V. Safety of epidural analgesia in the perioperative care of patients undergoing cytoreductive surgery with hyperthermic intraperitoneal chemotherapy. Ann Surg Oncol. 2014;21 (5):1487-1493. doi:10.1245/s10434-013-3221-1

7. Cata JP, Nguyen LT, Ifeanyi-Pillette IC, et al. An assessment of the survival impact of multimodal anesthesia/analgesia technique in adults undergoing cytoreductive surgery with hyperthermic intraperitoneal chemotherapy: a propensity score matched analysis. Int $J$ Hyperthermia. 2019;36(1):369-375. doi:10.1080/ 02656736.2019 .1574985

8. Owusu-Agyemang P, Cata JP, Fournier KF, et al. Evaluating the impact of total intravenous anesthesia on the clinical outcomes and perioperative NLR and PLR profiles of patients undergoing cytoreductive surgery with hyperthermic intraperitoneal chemotherapy. Ann Surg Oncol. 2016;23(8):2419-2429. doi:10.1245/s10434-016-5176-5

9. Owusu-Agyemang P, Cata JP, Meter AV, et al. Perioperative factors associated with persistent opioid use after extensive abdominal surgery in children and adolescents: a retrospective cohort study. Paediatr Anaesth. 2018;28(7):625-631. doi:10.1111/pan.13386

10. Peltoniemi MA, Hagelberg NM, Olkkola KT, Saari TI. Ketamine: a review of clinical pharmacokinetics and pharmacodynamics in anesthesia and pain therapy. Clin Pharmacokinet. 2016;55 (9):1059-1077. doi:10.1007/s40262-016-0383-6 
11. Riddell JM, Trummel JM, Onakpoya IJ. Low-dose ketamine in painful orthopaedic surgery: a systematic review and meta-analysis. $\mathrm{Br}$ J Anaesth. 2019;123(3):325-334. doi:10.1016/j.bja.2019.05.043

12. Elia N, Tramèr MR. Ketamine and postoperative pain - a quantitative systematic review of randomised trials. Pain. 2005;113(1):61-70. doi:10.1016/j.pain.2004.09.036

13. Anwar S, Cooper J, Rahman J, Sharma C, Langford R. Prolonged perioperative use of pregabalin and ketamine to prevent persistent pain after cardiac surgery. Anesthesiology. 2019;131(1):119-131. doi:10.1097/ALN.0000000000002751

14. Klatt E, Zumbrunn T, Bandschapp O, Girard T, Ruppen W. Intra- and postoperative intravenous ketamine does not prevent chronic pain: a systematic review and meta-analysis. Scandinavian J Pain. 2015;7 (1):42-54. doi:10.1016/j.sjpain.2014.12.005

15. De Kock M, Lavand'homme P, Waterloos H. "Balanced analgesia" in the perioperative period: is there a place for ketamine? Pain. 2001;92 (3):373-380. doi:10.1016/S0304-3959(01)00278-0

16. Cogan J, Lalumière G, Vargas-Schaffer G, Deschamps A, Yegin Z. Low-dose intravenous ketamine for postcardiac surgery pain: effect on opioid consumption and the incidence of chronic pain. Ann Card Anaesth. 2017;20(4):395. doi:10.4103/aca.ACA_54_17

17. Garcia-Navia JT, Tornero Lopez J, Egea-Guerrero JJ, Vilches Arenas A, Vazquez Gutierrez T. Effect of a single dose of lidocaine and ketamine on intraoperative opioids requirements in patients undergoing elective gynecological laparotomies under general anesthesia. A randomized, placebo controlled pilot study. Farm Hosp. 2016;40(1):44-51.

18. Brinck EC, Tiippana E, Heesen M, et al. Perioperative intravenous ketamine for acute postoperative pain in adults. Cochrane Database Syst Rev. 2018;12:Cd012033.

19. Modesitt SC, Sarosiek BM, Trowbridge ER, et al. Enhanced recovery implementation in major gynecologic surgeries. Obstet Gynecol. 2016;128(3):457-466. doi:10.1097/AOG.0000000000001555

20. Pouraghaei M, Moharamzadeh P, Paknezhad SP, Rajabpour ZV, Soleimanpour H. Intranasal ketamine versus intravenous morphine for pain management in patients with renal colic: a double-blind, randomized, controlled trial. World J Urol. 2020;39(4):1263-1267.
21. Kim SH, Kim SI, Ok SY, et al. Opioid sparing effect of low dose ketamine in patients with intravenous patient-controlled analgesia using fentanyl after lumbar spinal fusion surgery. Korean $J$ Anesthesiol. 2013;64(6):524. doi:10.4097/kjae.2013.64.6.524

22. Neil MJ, Macrae WA. Post surgical pain- the transition from acute to chronic pain. Rev Pain. 2009;3(2):6-9. doi:10.1177/ 204946370900300203

23. Chan MT, Wan AC, Gin T, Leslie K, Myles PS. Chronic postsurgical pain after nitrous oxide anesthesia. Pain. 2011;152(11):2514-2520. doi:10.1016/j.pain.2011.07.015

24. Chan MT, Peyton PJ, Myles PS, et al. Chronic postsurgical pain in the Evaluation of Nitrous Oxide in the Gas Mixture for Anaesthesia (ENIGMA)-II trial. Br J Anaesth. 2016;117(6):801-811. doi:10.1093/ bja/aew338

25. Peyton PJ, Wu C, Jacobson T, Hogg M, Zia F, Leslie K. The effect of a perioperative ketamine infusion on the incidence of chronic postsurgical pain-a pilot study. Anaesth Intensive Care. 2017;45(4):459-465.

26. Chaparro LE, Smith SA, Moore RA, Wiffen PJ, Gilron I. Pharmacotherapy for the prevention of chronic pain after surgery in adults. Cochrane Database Syst Rev. 2013;(7):CD008307.

27. Carley ME, Chaparro LE, Choinière M, et al. Pharmacotherapy for the prevention of chronic pain after surgery in adults: an updated systematic review and meta-analysis. Anesthesiology. 2021;135 (2):304-325. doi:10.1097/ALN.0000000000003837

28. Nielsen RV, Fomsgaard JS, Siegel H, et al. Intraoperative ketamine reduces immediate postoperative opioid consumption after spinal fusion surgery in chronic pain patients with opioid dependency: a randomized, blinded trial. Pain. 2017;158(3):463-470. doi:10.1097/j.pain.0000000000000782

29. Chumbley GM, Thompson L, Swatman JE, Urch C. Ketamine infusion for $96 \mathrm{hr}$ after thoracotomy: effects on acute and persistent pain. Eur J Pain. 2019;23(5):985-993. doi:10.1002/ejp.1366

30. Hayes C, Armstrong-Brown A, Burstal R. Perioperative intravenous ketamine infusion for the prevention of persistent post-amputation pain: a randomized, controlled trial. Anaesth Intensive Care. 2019;32 (3):330-338. doi:10.1177/0310057X0403200305
Journal of Pain Research

\section{Publish your work in this journal}

The Journal of Pain Research is an international, peer reviewed, open access, online journal that welcomes laboratory and clinical findings in the fields of pain research and the prevention and management of pain. Original research, reviews, symposium reports, hypothesis formation and commentaries are all considered for publication. The manuscript management system is completely online and includes a very quick and fair peer-review system, which is all easy to use. Visit http:// www.dovepress.com/testimonials.php to read real quotes from published authors. 